\title{
Determinants of Expected Wages of Unemployed Workers in Turkey
}

\author{
İsmail Şentürk \\ Department of Economics, Gaziosmanpaşa University, Tokat, Turkey \\ Email: ismail.senturk@gop.edu.tr
}

Received 22 June 2015; accepted 12 July 2015; published 15 July 2015

Copyright (c) 2015 by author and Scientific Research Publishing Inc.

This work is licensed under the Creative Commons Attribution International License (CC BY).

http://creativecommons.org/licenses/by/4.0/

(c) (i) 0 pen Access

\begin{abstract}
In this study, determinants of expected wages of unemployed individuals in Turkey have been analyzed. In addition to duration of unemployment, reservation wage, and previous wage, the effect of demographic and economic factors has also been studied. The data which were obtained from 1607 individuals who were included in a nationwide survey has been analyzed by the two stage least squares method. Our findings show that previous wage, age, level of education, number of foreign languages spoken, number of job offers the individual receives, and whether the individual receives state assistance determine the expected wage. Obtained results are important because they show how individuals price the variables that determine their own productivities. In addition, our study sheds light on relationships between reservation wage, duration of unemployment, previous wage, and expected wage within the context of Turkey.
\end{abstract}

\section{Keywords}

Expected Wages, Reservation Wages, Unemployment Duration, Unemployed, Turkey

\section{Introduction}

During the job search process, unemployed individuals form a wage expectation by taking into account their individual qualifications, market conditions, and their past experiences. This is called the "expected wage".

In economic theories, expectations take on an important role. Therefore, expectations of households (or individuals), one of the decision-making units, are important. Individuals constitute the only source of the labor factor. Therefore, the expectations of individuals and an explanation of the factors that affect these expectations are important.

The objective of this study is to determine whether the unemployed's personal qualifications, economic conditions during their unemployed period, and factors such as reservation wage and duration of unemployment, affect the wage they expect to get in the market. 
Whether wage expectations play a signal role in the foresights about labor market is a debated issue, therefore this topic is unique in the studies [1]. However, the wage expectations of individuals do play an important role in their work decisions. Individuals who cannot obtain their expected wage in the market may pull out of the market altogether or change sectors. When individuals pull out of the labor market or invest in changing sectors, a decrease in the efficiency of the labor factor may occur. Determining the factors that shape the unemployed's wage expectations may facilitate the prevention of these kinds of inefficiencies in the market.

Individuals price their qualifications and form a wage expectation. For example, individuals who have a high level of education raise their wage expectations to get a return on their educational investment. Likewise, individuals who have an occupation increase their wage expectations because they think they deserve a higher wage. Although individuals may desire higher wages based on their qualifications, as they move along the job search process, they get a better understanding of employers' expectations and adjust their wage expectations accordingly. Therefore, it is reasonable to suggest that the duration of a job search has an important corrective effect on expected wages and makes these expectations more realistic from the perspective of market knowledge.

When the unemployed get job offers, they compare the offered wage to the expected wage. The difference between the offered wage and expected wage (or the wage that the unemployed person thinks he deserves) becomes an important factor in the decision to take the offer or not.

An understanding of the process of developing wage expectations will assist job-seekers to form more rational estimates of employer expectations in regards to salary. Therefore, this study will contribute to a more accurate formulation of decision-making within the supply and demand dimensions of the labor market.

This introductory section of the study is followed by reviews of the literature, explanations of the data and methodology, analysis results, and suggestions.

\section{Literature Review}

There are few studies on wage expectations in current literature. Some of the existing studies research the effects of expected wages. Yuhong and Johnes’ (2003) [2] study of Mongolia can be cited as an example. In their study, the researchers analyzed the effect of expected wages on the occupational choices of students.

Other studies analyze wage expectations of university students. Borrego and Medina (2014) [3] found that academic performance and household environments of first year students had an effect on the expected wage. For students in other grades, they found that degree type and length of study affected expected wage but performance and household environments did not. Also, the studies of Dominitz (1998) [4], Das and van Soest (1999) [5], Webbink and Hartog (2004) [6] and Jerrim (2009) [7] are among those in which wage expectations of students are analyzed.

Maani and Studenmund's (1986) [8] study, analyzing wage expectations of unemployed individuals, analyzed the Chile example from a developing country perspective. In this study in which they used the two stage least squares method, they found that duration of unemployment had a negative effect on expected wage whereas previous wage, education, age, and job seeking methods had positive effects. Another noteworthy aspect of this study is that they determined that there was no significant relationship between experience and expected wage. While Kalb and Scutella (2002) [9] obtained similar findings to Maani and Studenmund (1986) [8] regarding education and age in Australia, they determined a positive and significant relationship between experience and expected wage.

Brown and Taylor (2009) [1] covered the UK to discover the determinants of expected wage. They found that wage expectations of males and elder individuals are high, and previous wage slightly increases wage expectations. They also determined that higher levels of education increased expected wage.

In another study, Brown and Taylor (2013) [10] also analyzed the determinants of expected wage in the UK. However, the focus of this study was the effect of the working family tax credit (WFTC), a policy change externally affecting the labor market, on expected wage. They found that implementation of the WTFC had a positive effect on expected wage.

\section{The Determinants of Expected Wages}

\subsection{Data}

In this study, the micro level data which was obtained from surveys conducted nationwide has been used. The 
survey has been conducted in a face-to-face manner in February and March of 2015 in 9 cities. A total of 1607 unemployed people were included from every region of Turkey. In addition, the surveys have been conducted at the Turkish Employment Agency, which is a state institution founded to establish links between employers and unemployed people. With this feature, a unique data set has been obtained.

In order to conduct surveys with the people who are in accordance with definition of "unemployed," the surveys were applied to those who "have no job, are seeking employment, and can start working in two weeks." Individuals were asked the question "What is the wage level you expect to get in these current market conditions?" and their expected wages were obtained. In addition, by asking, "How many hours do you want to work when you find a suitable job?” weekly work hours were obtained. As a result of dividing expected wage by the weekly work hours the expected wage per hour was found.

The population of the study is comprised of unemployed people between the ages of 16 and 65 . While determining the sample, numbers of unemployed people in different regions of Turkey were taken and survey numbers were determined in accordance with the ratio of unemployed people in that region to the total number of unemployed people in the country. Also, survey numbers were distributed in accordance with unemployed people by gender. As a result, the total sample size is 1607 . Of this figure, $60.7 \%$ is male and $39.3 \%$ is female.

\subsection{Method}

The regression equation used in the study is presented below.

$$
\ln (e w)_{i}=\alpha_{1 i} X_{i}+\alpha_{2} \ln (r w)_{i}+\alpha_{3} \ln (u d)_{i}+\alpha_{4} \ln (l w)+\varepsilon_{i}
$$

where dependent variable $\ln (e w)$ represents the natural logarithm of hourly expected wage, $\ln (r w)$ denotes the natural logarithm of hourly reservation wage, $\ln (u d)$ denotes the natural logarithm of unemployed duration, and $\ln (l w)$ denotes the natural logarithm of previous wage. The vector $X$ is the vector that contains the explanatory variables that are determinants of expected wage.

In Equation (1), when the partial derivative of $\ln (e w)$ with respect to $\ln (r w)$ is taken by using the chain rule twice, it is possible to reach the elasticities.

$$
u=\ln (e w), \quad v=\ln (r w) \quad \text { ve }(r w)=\mathrm{e}^{\ln (r w)}=\mathrm{e}^{\mathrm{v}}
$$

If

$$
\begin{aligned}
\frac{\partial \ln (\text { ew })}{\partial \ln (r w)} & =\frac{\partial u}{\partial v}=\frac{\partial u}{\partial(\text { ew })} \frac{\partial(\text { ew })}{\partial(r w)} \frac{\partial(r w)}{\partial v}=\left(\frac{\partial}{\partial(\text { ew })} \ln (\text { ew })\right)\left(\frac{\partial(\text { e } w)}{\partial(r w)}\right)\left(\frac{\partial}{\partial v} \mathrm{e}^{\mathrm{v}}\right) \\
& =\frac{1}{(\text { ew })} \frac{\partial(\text { ew })}{\partial(r w)} e^{\mathrm{v}}=\frac{1}{(\text { ew })} \frac{\partial(\text { ew })}{\partial(r w)}(r w)=\frac{\partial(\text { e } w)}{\partial(r w)} \frac{(r w)}{(\text { ew })}
\end{aligned}
$$

In short,

$$
\frac{\partial \ln (e w)}{\partial \ln (r w)}=\frac{\partial(e w)}{\partial(r w)} \frac{(r w)}{(e w)}
$$

is obtained.

We obtain the partial derivative of $\ln (e w)$ with respect to $\ln (u d)$ and partial derivative of $\ln (e w)$ with respect to $\ln (I w)$ as follows:

$$
\frac{\partial \ln (\text { ew })}{\partial \ln (u d)}=\frac{\partial(\text { ew })}{\partial(u d)} \frac{(u d)}{(e w)}
$$

and

$$
\frac{\partial \ln l(e w)}{\partial \ln (l w)}=\frac{\partial(e w)}{\partial(l w)} \frac{(l w)}{(e w)}
$$

Thus, in the Equation (1) $\alpha_{2}, \alpha_{3}$ and $\alpha_{4}$ denotes reservation wage elasticity, unemployed duration elasticity, and previous wage elasticity of expected wage, respectively. In other words, $\alpha_{2}$ shows the percentage 
change observed in the expected wage as a result of a one percent change in reservation price, $\alpha_{3}$ shows the percentage change observed in the expected wage as a result of a one percent change in duration of unemployment and $\alpha_{4}$ shows the percentage change observed in the expected wage as a result of a one percent change in the previous wage.

One of the problems encountered in the study is that the reservation wage stated by the individuals can contain some deviations, the reasons being that questions about reservation wage may not be quite understood [11], when a job opportunity arises people may accept a wage that is lower than what they stated [12] and people may answer according to the wage they think they should get, not the wage they can get [13]. These deviations cause the "reservation wage" not to give desired information. To avoid these deviations, the surveyed people were first explained the meaning of "reservation wage." Later, they were asked if they would work at a wage level slightly below the reservation level they stated. This question was repeated until the individuals gave the answer, "No, I won't work at a lower wage level than this". Thus, this obtained final answer was recorded as the real reservation wage at which the person is indifferent between working and not working.

Since people who had never been employed were also included in the data set, previous wages of these workers were recorded as zero. However, in order to be able to calculate the previous wage elasticity of expected wage, it should be possible to take the natural logarithm of the previous wage. Since a logarithm of zero cannot be taken, all the previous wages were valued at " 1 ". This addition will cause some changes in the results. However, this change it is negligible and can be ignored. In addition, in order to prevent from a heteroskedasticity problem, the square of the age variable has been added to the regression.

The vector $\mathrm{X}$ in Equation (1) contains the standard human capital earnings function, which was developed by Mincer (1974) [14], as well as different social demographic and economic variables. In line with Mincer’s (1974) [14] approach, the variables representing gender, level of education, and previous work experience (duration under social security coverage, apprenticeship period, vocational training) are some of the variables that constitute the vector X. Also, knowledge of foreign languages, number of job offers received, existing disabilities, and receiving or not receiving state assistance were included in the vector $\mathrm{X}$. Explanations and descriptive statistics of these variables in the questions are presented in Table 1.

Consistent with the findings of previous studies, Maani and Studenmund (1986) [8], Kalb and Scutella (2002)

Table 1. Descriptive statistics of the variables.

\begin{tabular}{|c|c|c|c|}
\hline Variables & Definition of the variables & Mean & St. Dev. \\
\hline $\ln E W$ & Natural logarithm of hourly expected wage & 2.038 & 0.332 \\
\hline $\ln U D$ & Natural logarithm of unemployment duration & 4.660 & 1.492 \\
\hline $\ln R W$ & Natural logarithm of hourly reservation wage & 1.864 & 0.310 \\
\hline$A G E$ & Age & 30.938 & 8.646 \\
\hline $\ln L W$ & Natural logarithm of the wage the person received from the previous job & 6.348 & 2.067 \\
\hline GENDER & Gender $(1=$ male, $0=$ female $)$ & 0.607 & 0.488 \\
\hline EDUC & $\begin{array}{l}\text { Education }(1=\text { illiterate, } 2=\text { elementary school, } 3=\text { secondary school, } \\
4 \text { = high school, } 5=\text { university, } 6=\text { master or higher })\end{array}$ & 3.857 & 1.158 \\
\hline VOCTRN & Sum of duration of vocational training ve apprenticeship period (in months) & 3.558 & 8.942 \\
\hline FORLANG & Number of foreign languages person speaks & 1.030 & 0.196 \\
\hline RESIDENT & Place of residence $(1=$ metropolis, $0=$ other $)$ & 0.641 & 0.480 \\
\hline JOBOFFER & Number of job offers received & 0.515 & 1.063 \\
\hline INSURNC & Duration under social security coverage (in months) & 48.712 & 55.118 \\
\hline DISAB & If the person has any disability $(1=$ yes, $0=$ no $)$ & 0.050 & 0.218 \\
\hline METHOD & Number of job seeking methods person uses & 2.299 & 1.110 \\
\hline COMPENS & $\begin{array}{l}\text { If the person receives unemployment aid or state assistance } \\
(0=\text { does not receive any, } 1=\text { receives one of them })\end{array}$ & 0.108 & 0.310 \\
\hline
\end{tabular}


[9], and Brown and Taylor (2009) [1], the signs of variables of age, gender, education, variety of job seeking methods, previous wage, experience, unemployment aid which reduces the cost of job seeking, and the status of receiving state assistance are expected to be positive.

It is probable that an increase in the person's age leads to a higher wage expectation. When the other conditions are equal, people expect a higher wages than those who are younger. In addition, males are thought to have a higher wage expectation than females because the probability of continued employment is not affected by special events like marriage or giving birth. This creates a positive relationship expectation between gender and expected wage.

In order to earn higher wage levels, people make educational investments. Therefore, as the level of education rises, people expect a wage that will provide an adequate return on their educational investment. The variety of job seeking methods can be considered a network that the person created. Expanding this network provides the individual with more opportunities to find a new job, thus enhancing his probability of obtaining a higher paying job based on his network and increasing his wage expectation.

The period a person is covered by social security has been used as the proxy of experience. An increase in a person's experience is expected to increase his wage expectations, and this is in line with previous studies since experienced people rationally assume their productivity will be higher than that of inexperienced people. In addition, previous job experience enhances a person's perception about his productivity and raises his wage expectation. Consequently, it is important to include previous wages in the analysis.

Payments received from unemployment benefits and state assistance reduce job-seeking costs but these incomes will cease when employment begins. Therefore, it is probable that people who have these types of incomes will expect higher wages to compensate for the loss of these incomes.

Two of the most important variables are "reservation wage" and "duration of unemployment." An increase in the reservation wage, which represents the lowest wage a person will accept, will carry the expected wage to a higher level because; people typically expect a higher rate of wage than the reservation wage. For example, Maani and Studenmund (1986) [8] determined that the average of the reservation wage was 32\% lower than the expected wage average. Duration of unemployment, however, can negatively affect the expected wage. An increase in the duration of unemployment can cause the person to lower his wage expectation.

Differing from previous studies, we used various variables that are thought to have an effect on expected wage. One of these variables is the sum of vocational training duration and apprenticeship period. In order to get a return for his investment in education, the person will increase his wage expectation. A similar situation is observed in the number of foreign languages a person speaks. The person makes the investment for foreign language education and thinks that this will increase his productivity. And he increases his wage expectation to get a return for his investment.

Another variable is the number of job offers the person receives. This variable can be considered as the variable that indicates how much this person is needed in the labor market and to what extent he has the qualifications employers desire. Therefore, an increase in job offers will lead to a higher wage expectation for the person.

Place of residence has been categorized as either "metropolis" or "others". Since the cost of living is higher in a metropolis, residents of these areas are expected to have higher wage expectations. In addition, since the productivity of people with disabilities is considered to be lower, this factor is expected to lower the expected wage.

According to the search model developed by Lippman and McCall (1976) [15], the expected wage of a worker is independently determined together with worker's reservation wage. It is assumed that as knowledge increases during the job search period, the job-seeking person updates his reservation wage [8]. From this perspective, the ordinary least squares method is considered suitable. However, as Sant (1977) [16] claimed, the person can determine his expected wage and reservation wage simultaneously. Since the independent variables in expected wage function can rank among the reservation wage function, in an OLS estimation, the expected wage can be correlated with error term. Thus, the OLS estimators will be biased. In this case, because the two stage least squares (2SLS) method takes simultaneity into account, it will be more practical and estimators can be obtained. In addition, in this method, as the sample size gets larger biasness will decrease and estimations will get closer to the values in the population.

\subsection{Findings}

Table 2 presents the 2SLS findings. Our findings show that previous wage, age, level of education, number of 
Table 2. Two stage least squares results.

\begin{tabular}{|c|c|c|c|c|}
\hline Variables & Coefficients & St. errors & t values & $\mathrm{P}$ values \\
\hline CONSTANT & 1.030 & 0.497 & 2.070 & 0.038 \\
\hline $\ln U D$ & -0.009 & 0.007 & -1.250 & 0.210 \\
\hline $\ln R W$ & -0.290 & 0.553 & -0.520 & 0.600 \\
\hline $\ln L W$ & $-0.012^{* *}$ & 0.005 & -2.290 & 0.022 \\
\hline$A G E$ & $0.052^{* *}$ & 0.020 & 2.550 & 0.011 \\
\hline AGE2 & $-0.001^{* *}$ & 0.000 & -2.460 & 0.014 \\
\hline GENDER & 0.038 & 0.024 & 1.590 & 0.113 \\
\hline$E D U C$ & $0.116^{*}$ & 0.043 & 2.690 & 0.007 \\
\hline VOCTRN & 0.001 & 0.001 & 0.410 & 0.679 \\
\hline FORLANG & $0.215^{*}$ & 0.069 & 3.120 & 0.002 \\
\hline RESIDENT & 0.008 & 0.021 & 0.370 & 0.710 \\
\hline INSURNC & 0.000 & 0.000 & 0.950 & 0.343 \\
\hline$D I S A B$ & -0.013 & 0.049 & -0.260 & 0.793 \\
\hline JOBOFFER & $0.028^{* *}$ & 0.014 & 2.020 & 0.043 \\
\hline METHOD & -0.008 & 0.010 & -0.800 & 0.421 \\
\hline COMPENS & $0.138^{* *}$ & 0.070 & 1.980 & 0.048 \\
\hline
\end{tabular}

Note: ${ }^{*},{ }^{* *}$ and ${ }^{* * *}$ show that the coefficients are statistically significant at 1,5 , and 10 percent significance levels.

foreign language spoken, number of job offers received, and state aids received have a significant effect on the expected wage. Age, level of education, number of foreign languages spoken, and increase in the number of job offers received increase the wage expectation. Wage expectations of unemployed people receiving state aids are higher than the ones who do not benefit from state assistance. These are conclusions that are in accord with the expectations. However, we determined that an increase in previous wage has a decreasing effect on expected wage. This finding is contrary to expectations and also shows the previous wage elasticity of expected wage. The elasticity has been found to be -0.012 . This value can be interpreted as "a $1 \%$ increase in the previous wage lowers the expected wage by $0.012 \%$," when all the other conditions are the same.

Another remarkable aspect in the findings is that unemployment duration and reservation wage do not have a significant effect on the expected wage. In the example of Turkey, it is seen that the lowest level of wage at which people consent to work and time period during which they stay unemployed do not have a determinative effect on their wage expectations. At the end of the analysis, gender, vocational training duration, place of residence, benefits from social security coverage, disabilities, and number of job seeking methods had no significant effect on the expected wage.

\section{Conclusions}

In this study, we analyzed the factors that determined the expected wages of unemployed individuals in Turkey. Expected wage also represents individuals' expectations about the value of their own qualifications in the job market. A survey was conducted nationwide for the study.

Age, level of education, and state aids received increase the wage expectation. In addition, that there is no significant relationship between experience and expected wage. Our findings on the relationship between previous wage and expected wage show negative relationship. Gender, variety of job-seeking methods, and experience variables had been found no significant effect on expected wages in our study.

One of the notable findings of our study is that no significant effect of unemployment duration and reservation wage is found on expected wage. This finding is different from previous studies. This shows that unem- 
ployed people develop their wage expectations independent of their unemployment duration and reservation wages. Particularly, the fact that an increase in unemployment duration does not change wage expectation is an interesting outcome.

The number of foreign languages spoken and the number of job offers received, which were not used in previous studies but were used in our study because they were determinants of expected wage, turn out to be positively related to the wage expectation. However, the vocation education variable does not have a significant effect. We conclude that individuals value knowledge like foreign language that can be used in many different fields more than professionally targeted vocational training. Likewise, despite not being used in previous studies in the literature, "place of residence" and "physical disability" variables used in our study were determined to have no significant effect on expected wage.

When we look closer at the findings, we see that with the 0.215 coefficient, the number of foreign languages the person speaks has the highest effect on expected wage. It is followed by receiving state aid (0.138), level of education (0.116), age (0.052), and number of job offers received (0.028).

This study is an attempt to determine the factors that shape unemployed individuals' wage expectations. We are of the opinion that the obtained findings will be useful for employers in making wage offers to prospective employees that better approximate the expectations of the job applicants. Employers who consider factors valued by unemployed people, such as foreign language, level of education, and age, will facilitate the formation of a more efficient labor market as the wage expectations of labor suppliers will be better met.

\section{Acknowledgements}

This study has been supported by Gaziosmanpasa University Scientific Research Projects Department with the project number 2015/61.

\section{References}

[1] Brown, S. and Taylor, K. (2009) Reservation Wages, Expected Wages and the Duration of Unemployment: Evidence from British Panel Data. IZA Discussion Paper No. 3981. http://ftp.iza.org/dp3981.pdf

[2] Yuhong, D. and Johnes, G. (2003) Influence of Expected Wages on Occupational Choice: New Evidence from Inner Mongolia. Applied Economics Letters, 10, 829-832. http://dx.doi.org/10.1080/1350485032000137477

[3] Alonso-Borrego, C. and Romero-Medina, A. (2014) Wage Expectations for Higher Education Students in Spain.

[4] Dominitz, J. (1998) Earnings Expectations, Revisions, and Realizations. Review of Economics and Statistics, 80, 374388. http://dx.doi.org/10.1162/003465398557618

[5] Das, M. and Van Soest, A. (1999) A Panel Data Model for Subjective İnformation on Household İncome Growth. Journal of Economic Behavior \& Organization, 40, 409-426. http://dx.doi.org/10.1016/S0167-2681(99)00062-1

[6] Webbink, D. and Hartog, J. (2004) Can Students Predict Starting Salaries? Yes! Economics of Education Review, 23, 103-113. http://dx.doi.org/10.1016/S0272-7757(03)00080-3

[7] Jerrim, J. (2009) Wage Expectations of UK Students: Are They Realistic? Southampton, UK, Southampton Statistical Sciences Research Institute, S3RI Applications and Policy Working Papers, 57 p. http://eprints.soton.ac.uk/63558/1/63558-01.pdf

[8] Maani, S.A. and Studenmund, A.H. (1986) The Critical Wage, Unemployment Duration, and Wage Expectations: The Case of Chile. Industrial \& Labor Relations Review, 39, 264-276. http://dx.doi.org/10.1177/001979398603900208

[9] Kalb, G.R. and Scutella, R. (2002) Estimation of Wage Equations in Australia: Allowing for Censored Observations of Labour Supply. Melbourne Institute Working Paper, The University of Melbourne. https://minerva-access.unimelb.edu.au/bitstream/handle/11343/33657/65783 0000009101 wp2002n08.pdf?sequence=1

[10] Brown, S. and Taylor, K. (2013) Reservation Wages, Expected Wages and Unemployment. Economics Letters, 119, 276-279. http://dx.doi.org/10.1016/j.econlet.2013.02.035

[11] Jones, S.R. (1988) The Relationship between Unemployment Spells and Reservation Wages as a Test of Search Theory. The Quarterly Journal of Economics, 103, 741-765. http://dx.doi.org/10.2307/1886073

[12] Hofler, R.A. and Murphy, K.J. (1994) Estimating Reservation Wages of Employed Workers Using a Stochastic Frontier. Southern Economic Journal, 60, 961-976. http://dx.doi.org/10.2307/1060433

[13] Petterson, S.M. (1997) Are Young Black Men Really Less Willing to Work? American Sociological Review, 62, 605613. http://dx.doi.org/10.2307/2657429

[14] Mincer, J.A. (1974) Schooling, Experience, and Earnings. NBER. 
[15] Lippman, S.A. and McCall, J. (1976) The Economics of Job Search: A Survey. Economic Inquiry, 14, 155-189. http://dx.doi.org/10.1111/j.1465-7295.1976.tb00386.x

[16] Sant, D.T. (1977) Reservation Wage Rules and Learning Behavior. The Review of Economics and Statistics, 59, 43-49. http://dx.doi.org/10.2307/1924902 